Proceedings of the 2006 Winter Simulation Conference

L. F. Perrone, F. P. Wieland, J. Liu, B. G. Lawson, D. M. Nicol, and R. M. Fujimoto, eds.

\title{
SIMULATING ORDER FULFILLMENT WITH PRODUCT SUBSTITUTIONS IN AN ASSEMBLE-TO-ORDER SUPPLY CHAIN
}

\author{
Thomas R. Ervolina, Markus Ettl, Young M. Lee \\ IBM T.J. Watson Research Center \\ P.O. Box 218 \\ Yorktown Heights, NY 10598, U.S.A.
}

\author{
Daniel J. Peters \\ IBM Integrated Supply Chain \\ 2070 Route 52 \\ Hopewell Junction, NY 12533, U.S.A.
}

\begin{abstract}
In today's competitive and dynamic business environment, companies need to continually evaluate the effectiveness of their supply chain and look for ways to transform business processes to achieve superior customer service and higher profitability. In this paper we propose a novel availability management process called Available-to-Sell (ATS) that incorporates demand shaping and profitable demand response to drive better operational efficiency through improved synchronization of supply and demand. We develop an order fulfillment simulation model to assess how the proposed availability management system affects supply chain performance, and apply the model in a server computer manufacturing environment. The simulation plays an important role in making strategic business decisions that impact customer service, revenue and profitability.
\end{abstract}

\section{INTRODUCTION}

In 2003 AMR Research described several key principles of $21^{\text {st }}$ century supply chain management and introduced the concept of Demand-Driven Supply Networks (DDSN). A Demand-Driven Supply Network is a system of technologies and business processes that senses and responds to real time demand across a network of customers, suppliers, and employees (O'Marah and Souza 2004; Cecere et al. 2005). DDSN principles require that companies shift from a traditional push-based supply chain to a pull-based, customer-centric approach. Companies that have adopted the DDSN business strategy have become more demand sensing, have more efforts on demand shaping and focus on a profitable demand response. Lee (2004) describes how leading companies have effectively built DDSN capabilities into their supply chains to attain a sustainable competitive advantage.

In this paper we describe a novel availability management process, called Available-to-Sell (ATS), that incorporates demand shaping and profitable demand response to drive better operational efficiency. The proposed process directly applies demand and supply data to better respond to changes in the marketplace. It utilizes intelligent product substitutions to mitigate short-term misalignments of supply and demand to enable companies to take full advantage of a "sell-what-you-have" strategy. The process involves generating an availability outlook that allocates available component supplies into Available-To-Promise (ATP) quantities of saleable end products based on current supply and demand. It is directly supported by an analytical optimization model that enables on demand up-selling, alternative-selling and down-selling to better integrate the supply chain horizontally, connecting the interaction of customers, business partners and sales teams to the procurement and manufacturing capabilities of a company. The business process is most effective in an assemble-to-order (ATO) environment where end products are configured from pluggable components.

The models and capabilities described in this paper enable companies to maintain a financially viable, profitable, and marketable product portfolio, take effective actions to avoid excess and surplus component inventory, and articulate marketable alternate product offerings. They can easily be imbedded into supply chain operations to improve day-to-day flexibility. For example, direct sales businesses that deal with customers directly through their website or telesales system can highlight featured products on-the-fly based on current component availability and steer customers towards product configurations that they can supply easily and profitably.

Ball et al. (2004) develop a general modeling framework for availability promising and present examples of ATP business practices from electronics companies including Dell and Toshiba. Chen et al. (2002) present a mixed integer programming model that provides an ATP order promising and fulfillment solution for batch orders that arrive within a predefined time interval. Ervolina and Dietrich (2001) describe an application of the implosion technology for ATP order promising in assemble-to-order (ATO) and configure-to-order (CTO) manufacturing environments. The goal is to create a feasible production plan that can be used to schedule or promise customer orders. Chen-Ritzo (2006) studies the availability management process for CTO system with order configuration uncertainty and formulates a two 
stage stochastic linear program with recourse that is solved using a sample average approximation method. Dietrich et al. (2005) describe an Available-To-Sell (ATS) implosion model that finds marketable products that consume the excess while minimizing additional component purchasing costs. Akcay and Xu (2004) develop a two-stage stochastic integer program with recourse to allocate constrained components so as to maximize the fraction of orders assembled within a quoted maximum delay. Balakrishnan and Geunes (2000) and Hale et al. (2001) study component and product substitution problems in ATO systems. Ettl et al. (2006) formulate the problem of finding marketable product alternatives in a given product portfolio as a non-linear program and develop an efficient column generation procedure for solving the problem. Balakrishnan et al. (2005) apply concepts from revenue management to investigate how a firm can maximize profits by shaping demand through dynamic pricing.

Industry best practices for demand shaping and demand response include identifying entry level products suitable for up-selling, changing marketed products based on supply position, providing product alternatives, and methods of continuous up-selling and cross-selling to meet financial objectives. To this end, a strong management system willing to make the nearly instantaneous decisions to drive the business forward is necessary, and must be supported by an integrated process and tool suite with sense and respond technologies, dynamic creation of up-sell and cross-sell relationships, and robust end-to-end analytics. Entry level products are often highlighted to customers to provide an interesting price-performance point that will establish a sound brand image and elicit a favorable customer response (i.e., buy decision) to direct or indirect marketing materials. These marketed entry level products are usually forecasted at a lower rate that actual demand, driving longer product availability lead times. The seller must have a reasonable supply line for the entry level products to meet regulatory and country specific business practices. The goal is to have customers contact the seller which provides the opportunity to up-sell the customer to a more richly configured solution, normally at a higher priceperformance point, usually thought of as the market "sweet spot" for the product category. One of the advantages of the sweet spot products is the improved lead time to ship or delivery availability over the entry level products determined due to forecasting greater sweet spot volumes. In a consumer society driven by having a product in next to real time, improved shipment or arrival lead times can be a compelling factor in a purchase decision.

The remainder of this paper is organized as follows. In section 2 we present the underpinning principles of availability management and discuss the advantages and disadvantages of different management approaches. In section 3 we present the problem definition and develop a simulation framework for modeling order fulfillment with product substitutions in an assemble-to-order supply chain. $\mathrm{Nu}$ merical findings and discussions of results are presented in section 4. This produces several insights into how advanced availability management can help proactively coordinate supply and sales, and it quantifies several business benefits in the context of assemble-to-order manufacturing. Section 5 concludes this paper.

\section{AVAILABILITY MANAGEMENT BUSINESS PROCESSES}

Availability management is the overarching task of balancing the planning of supply and demand and the execution of supply and demand. To achieve this task, companies have developed business processes that coordinate the flow of subtasks along with the use of information technology and decision support.

\subsection{Available-to-Promise (ATP)}

The planning side of availability management is administered by a Sales and Operations Planning (S\&OP) process. The goal of S\&OP is to generate a single plan of product availability that incorporates a company's revenue targets, unbiased demand forecasts, and the capacity of its supply chain. This plan is called the Available-to-Promise (ATP) schedule. The ATP schedule establishes a unified direction to which the sales and marketing teams will drive selling activities, the supply chain will plan to procure supply, and the finance teams will target revenue and earnings.

The execution side of availability management deals with a real-time stream of customer orders where each order must be scheduled or promised. As a customer request arrives, the order scheduling process must promise an availability date to the customer. This task involves checking the contents of the order against the ATP schedule, determining an availability promise date to the customer, and decrementing the ATP to accurately reflect the supply committed to new customer orders. The ATP schedule is the main linkage between availability management planning and execution as shown in Figure 1.

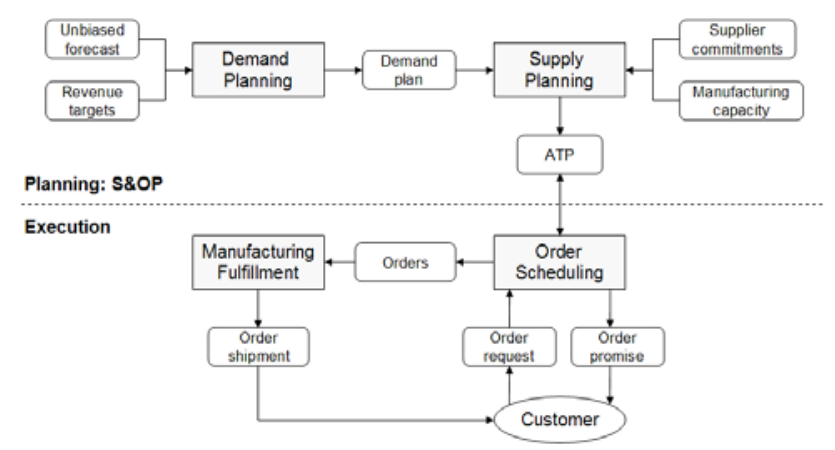

Figure 1: Availability Management with Available-ToPromise (ATP) 
The ATP process utilizes an analytical technique called implosion to generate an optimized ATP schedule that takes into account supplier commitments and limited manufacturing capacities (e.g., Dietrich et al. 2005). Because the implosion technology has no means of dealing with unallocated supply, a separate non-integrated business process is often created to manage inventory excess and overages, e.g. by exercising buy-back agreements with component suppliers or other procurement related techniques.

\subsection{Available-To-Sell (ATS)}

We propose a new concept for advanced availability management, called Available-to-Sell (ATS) that is gaining more and more traction with high-technology manufacturers that rely on suppliers to provide various materials and components needed to build finished products. ATS is designed to intelligently find alternative product configurations that best consume excess supply while minimizing additional procurement investments to build "squared" sets of components (i.e., complete sets of components needed to produce the finished products). Figure 2 illustrates the integration of ATP and ATS into an event-driven availability management process.

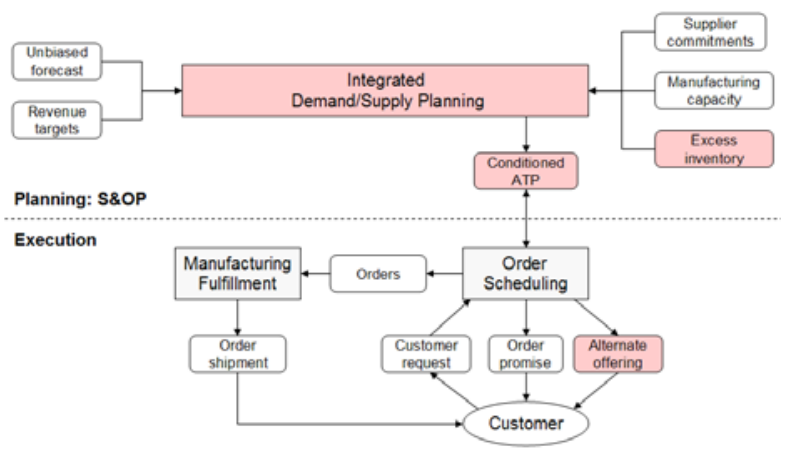

Figure 2: Availability Management with Available-To-Sell (ATS)

ATS seeks to ensure that the additional product availability is sellable and not in conflict with sales and marketing goals. The key output of the integrated process is a "conditioned" ATP schedule that comprises optimized ATP quantities of core products as well as ATP quantities of saleable product alternatives. The conditioned ATP schedule may take advantage of up-sell, alternate-sell or down-sell opportunities. An up-sell opportunity is where a customer or business partner is sold a more richly configured solution above the customer's initially selected price range. Incentives may be used to entice the customer to agree to an up-sell. An alternative-sell relates to a sale of a similar product that falls within the selected price range. An alternative-sell is performed when an up-sell is not available or the customer opts for a similarly priced product. A down-sell opportunity refers to a sale of a product that falls below the price range selected by the customer.

The integrated process is most effective in an assemble-to-order (ATO) supply chain environment where end products are configured from pluggable components and where customers can configure personalized products by selecting options from different feature categories such as hard disks, microprocessors, video cards, etc. In an ATO environment component supply is generally more flexible and the simplified product structure makes it more likely that product substitutions will drive customer demand.

\section{MODELING APPROACH}

In this section we formulate a mathematical programming model for ATS that generates the conditioned ATP. We also define the customer behavior model and describe the simulation framework that we have developed for conducting numerical experiments.

\subsection{Notation}

Before we state the problem formulation, we define the notation that is used throughout the paper.

\section{Products and components}

$I \quad$ : set of components

$P \quad$ : set of end products

$C \quad$ : set of core end products (core portfolio)

$S \quad$ : set of alternative end products (extended portfo-

lio) where $C \cup S=P$.

Demand and supply

$D_{j t} \quad:$ demand forecast for product $j \in C$ in period $t$

$D_{j t}^{\max } \quad$ : upside demand flexibility for product $j \in C$ in

period $t$ (note that $D_{j t}^{\max } \geq D_{j t}$ )

$S_{i t} \quad$ : supply of component $i \in I$ in period $t$

Bills-of-materials

$B_{i j} \quad: 1$ if product $j$ requires component $i, 0$ otherwise $i \in I, j \in P$

$A_{j k} \quad: 1$ if product $k \in S$ can be sold as a substitute for product $j \in C, 0$ otherwise.

Costs and profit

$p_{j} \quad:$ price of end product $j \in P$

$w_{j} \quad:$ profit of end product $j \in P$ 
$a_{j k} \quad$ : penalty cost of substituting one unit of product $k \in S$ for one unit of product $j \in C$ in the ATP schedule where $A_{j k}=1$.

\section{Decision variables}

$Y_{j t} \quad$ : ATP quantity for $j \in P$ in period $t$.

$E_{i t} \quad$ : excess inventory of component $i \in I$ in period $t$.

$X_{j k t} \quad:$ ATP quantity of end product $k \in S$ used as a substitute for end-product $j \in C$ in period $t$.

\subsection{ATS Problem Formulation}

Inputs to the optimization model are a core product portfolio, and extended product portfolio, and the demand forecast for core products. The core portfolio contains currently featured products that are offered by the seller whereas the extended portfolio contains alternative products. The alternative products may be used to fulfill unsatisfied demand for core products with additional substitution cost incurred. The components used to configure a saleable product are divided into feature categories where each component belongs to exactly one category. A bill-ofmaterial describes the set of components needed to produce each product in the core portfolio and the extended portfolio.

The goal of the optimization is to build enough volume to satisfy the demand forecast for each core product. If that can not be achieved, the model creates a conditioned ATP schedule with alternate products. The objective shown in (1) is to maximize a financial objective in period $t$ comprising of profit from sales, inventory holding costs and product substitution costs. Product substitution costs model any costs incurred for using an alternative product to fulfill demand for a core product. Backlogging is modeled as a lost profit opportunity.

$$
\max \sum_{j \in P} w_{j} Y_{j t}-\sum_{j \in C} \sum_{k \in S} a_{j k} X_{j k t}-\sum_{i \in I} h_{i} E_{i t}
$$

Let us now formulate the constraints. The ATP quantity for product $j, Y_{j t}$, is allowed to exceed the demand, $D_{j t}$, but is strictly bounded by the upside demand flexibility limit $D_{j t}^{\max }$. An internal cost discount is applied to the portion of the ATP quantity that exceeds the demand. This forces ATS to build up to the nominal demand of a product before building upside flexibility for any other product.

$$
Y_{j t}+\sum_{k \in S} X_{j k t} \leq D_{j t}^{\max }, \forall j \in C
$$

The ATP schedule must be feasible with respect to the component supply, i.e., the number of components consumed plus any unallocated inventory must be equal to the available component supply:

$$
\sum_{j \in P} B_{i j} Y_{j t}+E_{i t}=S_{i t}, \forall i \in I
$$

Finally we impose non- negativity constraints on the decision variables:

$$
\begin{aligned}
& Y_{j t} \geq 0, \forall j \in P \\
& E_{i t} \geq 0, \forall i \in I \\
& X_{j k t} \geq 0, \forall j \in C, k \in S
\end{aligned}
$$

The optimization problem (1)-(6) is a linear program that can be solved very efficiently even for large problem sizes. Notice that there is no explicit demand forecast for products in the extended portfolio, and core products are not sold as alternatives for other core products. Furthermore, while there is an upside flexibility limit on the demand for each core product, there is no limit on how many alternative products can be made available in the ATP schedule. However, observe that the total ATP quantity across all products in period $t$ is limited to sum of the upside demand flexibility values $D_{j t}^{\max }$ for all $j \in C$.

\subsection{Customer Behavior Model}

Demand is principally shaped by performance, price and availability. Sound conditioning relies upon shaping client perceptions and expectations of the seller's product portfolio's value. We next describe our customer behavior model and explain how customers evaluate alternative products if their initial product selection is unavailable.

Each customer has an associated price sensitivity parameter $\alpha$ that determines the incremental price that the customer is willing to pay for an alternative product, and a quality sensitivity parameter $\beta$ that determines the customer's valuation of quality. The customer's price sensitivity is modeled by a reservation price. In particular, if a customer's initial purchase is for product $j$ and $p_{j}$ denotes the price of product $j$, the customer's reservation price is drawn uniformly from the interval $\left[p_{j},(1+\alpha) p_{j}\right]$. Similarly, the customer's quality sensitivity is modeled by a reservation utility. If $q_{j}$ denotes the quality level of product $j$, the customer's reservation utility is drawn uniformly from the interval $\left[(1-\beta) q_{j}, q_{j}\right]$. Following standard practice, we compute the quality level of a product as the 
(weighted) average of the quality scores of the components used in its configuration. Each component in a commodity group is assigned a quality score (a value between 0 and 100) based on its quality relative to all other components in the same commodity group. Higher scores are assigned to components with higher parts worth, e.g., a 120GB hard disk will score higher than a 60GB hard disk.

The price sensitivity and quality sensitivity together determine whether customers will consider an alternative product $k$ if their initial selection $j$ is currently unavailable. Customers are willing to purchase an alternative product if its price does not exceed their reservation price and if its quality is no less than their reservation utility. If no alternative selections in the desired quality range are available or exceed the customer's reservation price, we assume that customers place a backorder for their initial selection.

\subsection{Simulation Framework}

The simulation model was built using the Availability Management Simulation Tool (AMST) that has been used for several years at IBM to develop various availability management simulation models (Lee 2006). AMST was developed using the simulation capabilities of IBM's WBI Modeler $^{\circledR}$ as a simulation modeling framework for availability management processes.

The simulation framework consists of reusable components and methods which are easily adapted for various availability management environments. The tool has been instrumental in evaluating and deploying several availability management transformation opportunities at IBM. The simulation model developed for this study interfaces with the ATS optimization engine to obtain ATP quantities, generates and schedules customer orders against the ATP, and simulates supply chain dynamics such as customer shopping behavior, reservation price, customer buying preferences, and variability of customer demand. Figure 3 illustrates the simulation model and its interaction with the ATS optimizer described in the previous subsection.

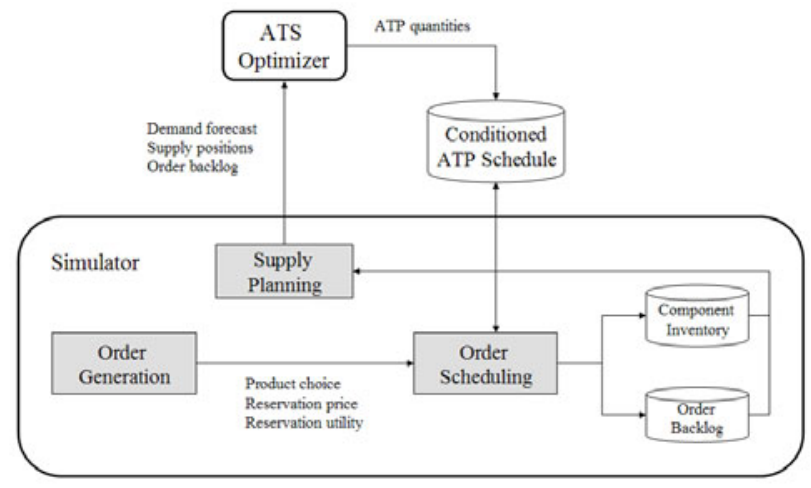

Figure 3: Availability Simulation Model and Interface to ATS optimization.
Customer orders are generated according to a demand forecast and other attributes such as product specification, price sensitivity and quality sensitivity. The orders are then processed and scheduled against ATP quantities. Here various order scheduling policies, such as up-sell policies, down-sell policies, priority scheduling, and incentives are simulated. When an order is scheduled, the ATP quantity of the scheduled product is decremented, and corresponding components are decremented from the inventory of components according to the bills-of-materials. At the end of a period, the supply-demand task is triggered to invoke the ATS engine which computes optimized ATP quantities based on the updated information on supply and demand and a new set of customer orders is generated. The simulation collects statistics on all relevant business performance metrics such as order backlog, serviceability, inventory holding costs, sales revenue and profit.

\section{SIMULATION STUDY}

We implemented the availability management models described in the previous section and applied them to an assemble-to-order (ATO) system for mid-range server computers. Through simulation analysis we examine the question of when ATS outperforms traditional availability management approaches such as ATP. In this section we present our numerical findings. First, we examine the effect of supply variability on the performance of the supply chain and compare ATS and ATP in terms of expected profit and delivery availability. Second, we investigate how a seller can take advantage of up-sell opportunities to advertise more richly configured solutions to customers for increased profit. Finally, we analyze the effect of customers' price sensitivity on profitability and examine how it influences the seller's demand shaping strategy.

\subsection{Model Description}

The example scenario for the numerical study is derived from a real-world problem compiled from actual server computer manufacturing data. The product portfolio consists of eight server computer products that represent a wide spectrum of price-performance points. The products and their bills-of-materials are depicted in Table 1. Product configurations $M_{1}$ and $M_{2}$ are entry-level products, $M_{3}$ to $\mathrm{M}_{6}$ are mid-range systems, and $\mathrm{M}_{7}$ and $\mathrm{M}_{8}$ are highperformance computers. Each product is assembled from one component of each of six different commodity groups: system processors, memory, hard drives, optical drives, video adapters and software preloads. For example, product $\mathrm{M}_{1}$ is assembled from a $2.8 \mathrm{GHz}$ system processor, a 30GB hard drive, 128MB memory, a 48X CD-RW optical drive, an Extreme $3 \mathrm{D}$ video card and a system software preload B. 
The table also shows the quality score and the cost of every component. The quality score of a component depends on its parts worth relative to the other components in the same commodity group. Components with the highest parts worth are assigned the highest quality score. We assume that the quality score of product $j, q_{j}$, is the average of the quality scores of all components used in its bill-of material. The sales price of product $j, p_{j}$, is the cumulative cost of the components after applying a 20 percent profit margin. The quality scores and sales prices of the product portfolio are displayed in the two bottom rows of Table 1.

Table 1: Bill-of-Materials Structure Used in the Simulation Study.

\begin{tabular}{|c|c|c|c|c|c|c|c|c|c|c|c|}
\hline \multicolumn{4}{|c|}{ Components } & \multicolumn{8}{|c|}{ Product Portfolio } \\
\hline Group & Technology & Quality & Cost & $\mathrm{M}_{1}$ & $\mathrm{M}_{3}$ & $\mathrm{M}_{3}$ & $\mathrm{M}_{4}$ & $\mathrm{M}_{3}$ & $\mathrm{M}_{4}$ & $\mathrm{M}_{7}$ & $\mathrm{M}_{1}$ \\
\hline \multirow{4}{*}{$\begin{array}{l}\text { SYSTEM } \\
\text { PROCESSORS }\end{array}$} & $2.8 \mathrm{CHz} 800 \mathrm{MHz}$ Xeon & 25 & 260 & 1 & 1 & & & & ? & & \\
\hline & $3.00 \mathrm{~Hz} 800 \mathrm{MHz}$ Xeon & 30 & 340 & . & & 1 & 1 & . & . & . & . \\
\hline & 3.2. $\mathrm{GHz} 800 \mathrm{MHz}$ Xeon & 75 & 420 & . & . & . & . & 1 & 1 & . & \\
\hline & 3. $4 \mathrm{GHz} 8 \mathrm{800 \textrm {MHz }} \mathrm{XeOn}$ & 100 & 500 & & & & & & & 1 & \\
\hline \multirow{4}{*}{ HARD DRIVES } & $30 \mathrm{~GB} 4200 \mathrm{RPM}$ & 20 & 100 & 1 & - & 1 & - & - & - & & \\
\hline & $40 \mathrm{~GB} 4200 \mathrm{RPM}$ & 40 & 140 & - & 1 & & & 1 & & - & - \\
\hline & $60 \mathrm{OB} 4200 \mathrm{RPM}$ & 60 & 180 & & & & 1 & & 1 & & \\
\hline & $\begin{array}{l}120 \mathrm{~GB} 7200 \mathrm{RPM} \\
160 \mathrm{BB} 7200 \mathrm{RPM}\end{array}$ & $\begin{array}{r}80 \\
100\end{array}$ & $\begin{array}{l}240 \\
300\end{array}$ & : & - & - & & - & : & 1 & \\
\hline \multirow{4}{*}{ MEMORY } & 128MB SDRAM & 20 & 80 & 1 & . & 1 & - & & . & & . \\
\hline & $256 \mathrm{MB}$ SDRAM & 40 & 120 & & 1 & & - & 1 & & & \\
\hline & 512MB SDRAM & 60 & 160 & - & - & & 1 & - & & & - \\
\hline & 1.0GB SDRAM & 80 & 200 & & & & & & 1 & 1 & ; \\
\hline \multirow{3}{*}{ OPTICAL DRIVES } & $\begin{array}{l}20 \text { GB SDAMM } \\
9.5 \mathrm{~mm} \text { Slim DVD }\end{array}$ & 30 & 70 & & 1 & 1 & . & & & & \\
\hline & $48 \mathrm{XCD} \cdot \mathrm{RW}$ & 40 & 90 & 1 & - & & $\therefore$ & 1 & : & 1 & 1 \\
\hline & 48X CD-RW/DVD Combo & 50 & 100 & & 7 & 1 & 1 & $T$ & & & \\
\hline \multirow{2}{*}{ VIDEO ADAPTER } & Extreme 3D Express & 40 & 150 & $i$ & : & : & 1 & . & 1 & 1 & 1 \\
\hline & Nvidia Adtanced 3D & 50 & 175 & & . & . & & . & & & \\
\hline \multirow{5}{*}{ SOFTWARE } & Preload A & 30 & 100 & & 1 & & - & & 1 & & \\
\hline & Preload B & 30 & 120 & 1 & & 1 & & 1 & & & \\
\hline & Preload C & 30 & 140 & & - & & 1 & & - & - & - \\
\hline & Preload D & 50 & 200 & - & - & - & - & - & - & 1 & ; \\
\hline & & & & & & & & & & & \\
\hline \multicolumn{4}{|l|}{ Product quality $q_{j}$} & 29 & 33 & 30 & 48 & 43 & 56 & 65 & 72 \\
\hline \multicolumn{4}{|c|}{ Product sales price $p_{f}$} & 960 & 978 & 1,002 & 1,284 & 1,218 & 1,380 & 1,656 & 1,836 \\
\hline
\end{tabular}

To model demand, we assume that $D_{j}=1,000$ customer orders for product $j$ arrive on average in each time period. For every customer order, the simulator randomly generates a reservation price and a reservation utility as described in section 3.3 to model the customer's propensity to purchase an alternative product. The price and quality sensitivity parameters used in the customer behavior model are assumed to be $\alpha=0.25$ and $\beta=0.10$ respectively.

To enable product substitutions, we defined five alternative products for each product configuration in the core portfolio. These include one down-sell product with a 5$10 \%$ lower price point than the core product, two alternative-sell products with a similar price and quality score, and two up-sell products that are priced 10-20 percent higher than the core product. For each customer order, the simulator first queries the conditioned ATP for the availability of an up-sell product within the reservation price of the customer. If none of the up-sell products are on hand, the simulator checks the ATP schedule for the customer's initial selection or an alternative-sell, and as a last resort for a down-sell product. Finally, if neither the customer's initial selection nor any qualified product substitution is available the order is backlogged. For all scenarios in our numerical study we conducted 15 independent replications and captured statistical outcomes for several performance metrics pertaining to supply chain responsiveness, order fulfillment performance, and profitability.

\subsection{Effect of Supply Variability}

Our first set of experiments shows that the ATS model can perform better than a traditional ATP model when the component supply deviates from the ideal net component requirements. We calculated the net component requirements by "exploding" the demand forecast through the billof-materials in a standard MRP-type calculation (e.g., Hopp and Spearman, 2000). This calculation yields an unbiased component mix for each commodity group which we used as a baseline. Subsequently we generated random supply scenarios and allowed the supply mix to deviate from the unbiased supply mix. The mean absolute percentage deviation from the unbiased supply mix varied between 10 and 25 percent across all components. Table 2 shows the simulation results for customer serviceability (i.e., the fraction of orders filled from on-hand inventory), order backlog, and sales profit.

Table 2: Performance Comparison Between ATP and ATS Under Different Supply Scenarios.

\begin{tabular}{|c|cc|rr|rrr|}
\hline $\begin{array}{c}\text { Supply mix } \\
\text { variability }\end{array}$ & \multicolumn{2}{|c|}{ Serviceability } & \multicolumn{2}{|c|}{ Order backlog } & \multicolumn{3}{c|}{ Sales profit } \\
& ATP & ATS & \multicolumn{1}{c|}{ ATP } & \multicolumn{1}{c|}{ ATS } & ATP & ATS & Rel. impr. \\
\hline $10 \%$ & $93.0 \%$ & $95.2 \%$ & 558 & 382 & $\$ 1,589,941$ & $\$ 1,630,891$ & $2.6 \%$ \\
$15 \%$ & $80.0 \%$ & $82.5 \%$ & 1,596 & 1,403 & $\$ 1,401,998$ & $\$ 1,460,260$ & $4.2 \%$ \\
$20 \%$ & $75.2 \%$ & $80.2 \%$ & 1,981 & 1,580 & $\$ 1,272,769$ & $\$ 1,335,744$ & $4.9 \%$ \\
$25 \%$ & $72.2 \%$ & $76.7 \%$ & 2,226 & 1,861 & $\$ 1,293,557$ & $\$ 1,372,438$ & $6.1 \%$ \\
\hline
\end{tabular}

We find that the percentage decrease in backlog resulting from ATS order scheduling over ATP is as high as 31\%. The relative improvement in total gross profit increases with the deviation from the ideal supply mix and is as high as $6.1 \%$. The reason is that the ATS optimizer can more effectively mitigate supply-demand imbalances and allocate supply to saleable product alternatives, thus reducing backlog and increasing sales, whereas ATP is restricted to allocating supply to products in the core product portfolio.

\subsection{Effect of Supply Skew}

As indicated in the introduction, sellers often feature entry level products in their marketing materials to provide a competitive price-performance point, but usually forecast these products at a lower rate than actual demand. Once contact with the customer is established (either via telesales personnel or a direct sales website), the seller explores the opportunity to up-sell the customer to a more 
richly configured product at a higher price-performance point for increased revenue and profitability. Table 3 shows three supply scenarios that are increasingly skewed towards higher value components within the three commodity groups processors, hard drives and memory. The ideal supply mix, derived from the net component requirements, is shown in the second column as a baseline.

Table 3: Scenarios for Low, Moderate and Heavy Component Supply Skew

\begin{tabular}{|c|c|c|c|c|c|}
\hline \multicolumn{2}{|c|}{ Components } & \multirow{2}{*}{\begin{tabular}{|c|}
$\begin{array}{c}\text { Unbiased } \\
\text { component mix }\end{array}$ \\
$25 \%$
\end{tabular}} & \multirow{2}{*}{\begin{tabular}{|c|}
$\begin{array}{c}\text { Biased } \\
\text { component mix } \\
\text { (low skew) }\end{array}$ \\
$24 \%$ \\
\end{tabular}} & \multirow{2}{*}{\begin{tabular}{|c|c}
$\begin{array}{c}\text { Biased } \\
\text { component mix } \\
\text { (moderate skew) }\end{array}$ \\
$26 \%$
\end{tabular}} & \multirow{2}{*}{\begin{tabular}{|c|}
$\begin{array}{c}\text { Biased } \\
\text { component mix } \\
\text { (heawy skew) }\end{array}$ \\
$19 \%$ \\
\end{tabular}} \\
\hline & $2.8 \mathrm{GHz} / 800 \mathrm{MHz}$ Xeon & & & & \\
\hline SYSTEM & 3.0 GHz $800 \mathrm{MHz}$ Xeon & $25 \%$ & $26 \%$ & $24 \%$ & $31 \%$ \\
\hline \multirow[t]{2}{*}{ PROCESSORS } & 3.2 $2 \mathrm{~Hz} / 800 \mathrm{MHz}$ Xeon & $25 \%$ & $25 \%$ & $23 \%$ & $20 \%$ \\
\hline & $3.4 \mathrm{GHz} / 800 \mathrm{MHz}$ Xeon & $25 \%$ & $25 \%$ & $28 \%$ & $30 \%$ \\
\hline \multirow{5}{*}{ HARD DRIVES } & $30 \mathrm{~GB} 4200 \mathrm{RPM}$ & $25 \%$ & $10 \%$ & $10 \%$ & $10 \%$ \\
\hline & $40 \mathrm{~GB} 4200 \mathrm{RPM}$ & $25 \%$ & $28 \%$ & $25 \%$ & $28 \%$ \\
\hline & $60 \mathrm{~GB} 4200 \mathrm{RPM}$ & $23 \%$ & $31 \%$ & $31 \%$ & $26 \%$ \\
\hline & $120 \mathrm{~GB} 7200 \mathrm{RPM}$ & $13 \%$ & $19 \%$ & $20 \%$ & $21 \%$ \\
\hline & 160GB 7200 RPM & $13 \%$ & $13 \%$ & $14 \%$ & $15 \%$ \\
\hline \multirow{5}{*}{ MEMORY } & 128MB SDRAM & $25 \%$ & $10 \%$ & $10 \%$ & $10 \%$ \\
\hline & 256MB SDRAM & $25 \%$ & $28 \%$ & $25 \%$ & $28 \%$ \\
\hline & 512MB SDRAM & $13 \%$ & $19 \%$ & $21 \%$ & $19 \%$ \\
\hline & 1.0GB SDRAM & $25 \%$ & $28 \%$ & $26 \%$ & $25 \%$ \\
\hline & $2.0 \mathrm{OB}$ SDRAM & $13 \%$ & $16 \%$ & $18 \%$ & $19 \%$ \\
\hline
\end{tabular}

Figure 4 displays the attainable profit and the number of alternative product purchases under an ATS regime when the seller takes advantage of up-sell opportunities. In addition to utilizing reservation prices and reservation utilities to determine whether a customer will consider an alternative product, we assume that a fraction of customers are committed to their first product choice and will not accept an alternative configuration. We assume that the firstchoice probability is 0.3 for customers of entry-level products $M_{1}$ and $M_{2} 0.5$ for mid-range products $M_{3}$ to $M_{6}$ and 0.7 for high-performance products $\mathrm{M}_{7}$ and $\mathrm{M}_{8}$.

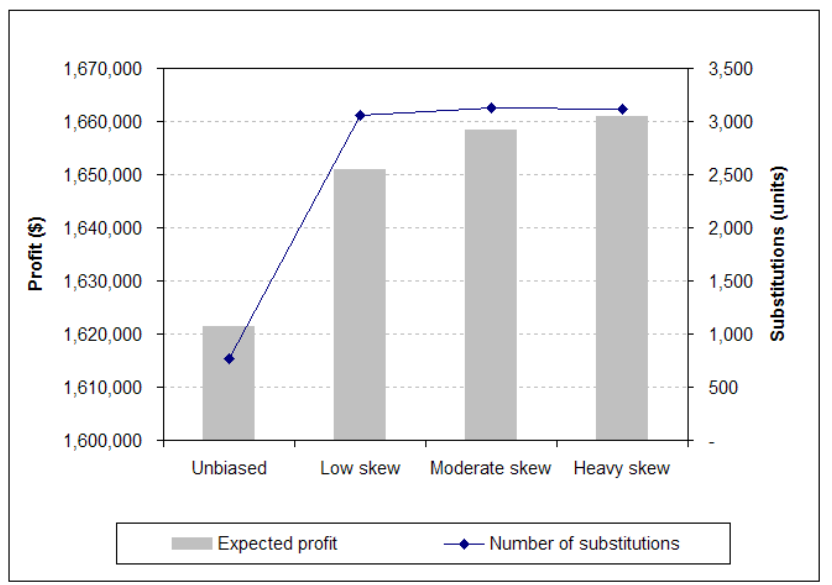

Figure 4: Expected Profit and Number of Substitutions with ATS Under Increasing Supply Skew.

It is clear from the figure that a skewed supply mix can result in $2-3 \%$ higher profitability over the unbiased case when supply is allocated intelligently to enable up-sell purchases. Slightly more than 3,000 customer orders - or $38 \%$ of the total orders - are filled with alternative products in the three biased supply scenarios. This number is largely independent of the degree of supply skew.

The fact that the relative profit increase is not more dramatic can be explained by noting that under the above first-choice model assumptions only 50 percent of customers consider an up-sell product alternative. Since a customer's price sensitivity is sampled from the interval $[0, .25]$, the average potential profit increase per up-sell is $12.5 \%$. A theoretical upper bound on the total profit improvement is thus $6.25 \%$. However, the attainable profit uplift is lower for several reasons: first of all, because the seller maintains a limited portfolio of alternative configurations, an up-sell purchase will normally not realize the reservation price of the customer; secondly, the majority of up-sell opportunities pertain to entry-level products that produce lower profits; and thirdly, customer orders with low sampled reservation prices may result in backlog (or down-sells) if the price point of the up-sell configurations offered by the seller is above the customer's price range.

\subsection{Effect of Price Sensitivity}

To analyze how the reservation price of customers can affect the seller's profitability, we used the heavily skewed supply scenario from the previous experiment and simulated the supply chain performance under different settings of the price sensitivity parameter $\alpha$. We examined four scenarios where $\alpha=.25, .50, .75$ and $\alpha=\infty$. Higher values of $\alpha$ imply that customers are less price sensitive. In the last scenario customers are price insensitive, i.e., they will accept an up-sell product regardless of price as long as the quality score meets or exceeds their reservation utility. Figure 5 shows the expected profit and number of alternative product purchases as a function of price sensitivity.

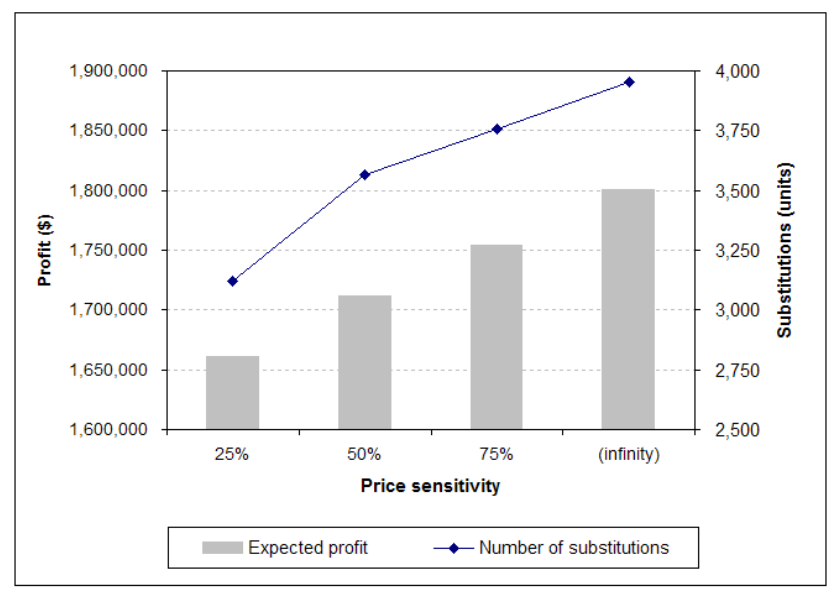

Figure 5: Expected Profit and Number of Substitutions for Different Values of the Price Sensitivity Parameter $\alpha$. 
In these examples, the ATS process results in substantially improved profits. When customers are price insensitive, the profit gain is as much as 11 percent above the baseline scenario with unbiased supply (recall that in our experiments the up-sell products are priced on average 15 percent higher than the corresponding core product). The boost in profitability is driven by the increased number of up-sell purchases, because as $\alpha$ increases the reservation price becomes a less dominant factor for completing a sale.

Figure 6 displays the effect of price sensitivity on order backlog and customer serviceability. As the reservation price parameter increases, the order backlog decreases because higher reservation prices translate into fewer customers rejecting an up-sell configuration when their first choice selection is unavailable. At the same time the reduced order backlog drives up customer serviceability as shown in the figure.

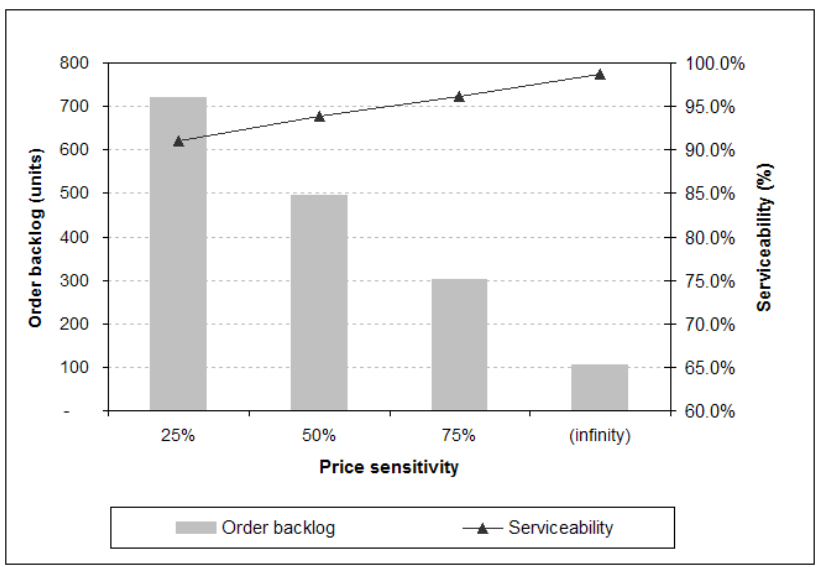

Figure 6: Order Backlog and Customer Serviceability for Different Values of the Price Sensitivity Parameter $\alpha$.

\section{SUMMARY AND OUTLOOK}

In this paper we have developed and simulated an advanced ATS availability management process for assemble-to-order supply chains and have outlined the business requirements for incorporating such a process into supply chain operations. The proposed approach aims at finding marketable product alternatives in a product portfolio that best utilize inventory surplus and replace demand on supply-constrained products. We have highlight the advantages of ATS through simulations with realistic production data. The models featured in this paper have already contributed to substantial business improvements in real-world supply chains. IBM has implemented an ATS process in its complex-configured server supply chain in 2002 . The realized savings include $\$ 100 \mathrm{M}$ of inventory reduction in the first year of implementation and over \$20M reduction annually in the subsequent years.
Credible product alternatives must be contained in any product portfolio and be presented to customers during the sales process. The business benefits of doing so in conjunction with an optimized ATS process are increased revenue, profitability, market share, and client satisfaction. Some additional financial benefits that directly impact the profit and loss statement are the cost avoidance of brokering, scrapping and inventory obsolescence, reduction of inventory carrying costs, return cash for additional investments, and improved cash-to-cash cycle times.

Future work would include the assessment of gaps within the product portfolio relative to performance, price and/or both, and the effect on profitability and the backlog. The product portfolio in this work had sufficient product alternatives for the demands placed. If a business had failed to provide adequate product coverage or prematurely withdrew the products from active marketing, then a determination on financial performance would be very interesting for the product development, sales, finance and demand/supply communities. Additionally, improvements in customer analytics such as propensity to buy and share of the wallet would provide greater insight into customer buying behavior and enhance the sound foundation of the current ATS modeling.

\section{ACKNOWLEDGMENT}

The authors wish to thank Haifeng Xi of IBM Research for his help with packaging and integrating the ATS system with the simulation environment.

\section{REFERENCES}

Akcay, Y. and S. Xu 2004. Joint inventory replenishment and component allocation optimization in an assemble-to-order system. Management Science 50, 99-116.

Balakrishnan, A. and J. Geunes. 2000. Requirements planning with substitutions: exploiting bill-of-materials flexibility in production planning. Manufacturing and Service Operations Management 2, 2. 166-185.

Balakrishnan, A., Y. Xia and B. Zhang. 2005. Shaping demand to match anticipated supply. MSOM Conference 2005. Northwestern University.

Ball, M.O, C.Y. Chen and Z.Y. Zhao. 2004. Available to promise. In: Simchi-Levi, D., Wu, S.D. and Shen, Z.J. (eds). Handbook of Quantitative Supply Chain Analysis - Modeling in the e-Business Era. Kluwer Academic Publishers. 447-480.

Cecere, L., D. Hofman, R. Martin and L. Preslan. 2005. The handbook for becoming demand driven. AMR Research.

Chen, C.-Y., Z. Zhao, and M.O. Ball. 2002. A model for batch advanced available-to-promise. Production and Operations Management 11, 424-440. 
Chen-Ritzo, C.-H. 2006. Availability management for configure-to-order supply chain systems. PhD Dissertation. Pennsylvania State University.

Dietrich, B., D. Connors, T. Ervolina, J.P. Fasano, R. Lougee-Heimer and R. Wittrock. 2005. Applications of implosion in manufacturing. In: An, C. and $\mathrm{H}$. Fromm (eds.). Supply Chain Management on Demand. Springer. 97-115.

Ervolina, T. and B. Dietrich. 2001. Moving toward dynamic available-to-promise. In: Gass, S. and Jones. A.T. (eds.) Supply Chain Management Practice and Research: Status and Future Directions. 1-19.

Ettl, M., P. Huang, K. Sourirajan, T.R. Ervolina and G.Y. Lin. 2006. Supply and demand synchronization in assemble-to-order supply chains. IBM Research Report RC 23923. http://domino.watson.ibm.com/library/CyberDig.nsf

Hale, W., D.F. Pyke and N. Rudi. 2001. An assemble-toorder system with component substitution. Working Paper. Tuck School of Business at Dartmouth.

Hopp, W. and M. Spearman. 2000. Factory Physics. $2^{\text {nd }}$ Edition. McGraw-Hill/Irwin.

Lee, H. 2004. The triple-A supply chain. Harvard Business Review 82, 10. 102-112.

Lee, Y. M. 2006. Analyzing the Effectiveness of availability management process. In Trends in Supply Chain Design and Management: Technologies and Methodologies. Jung, H., Chen, F.F., Jeong, B., (eds.). Springer, forthcoming.

O'Marah, K. and J. Souza. 2004. DDSN: $21^{\text {st }}$ century supply on demand. AMR Research.

\section{AUTHOR BIOGRAPHIES}

TOM ERVOLINA is a Research Staff Member in the Math Sciences Department at IBM's T.J. Watson Research Center. His research interests are in resource allocation models for Supply Chain Management. Tom joined IBM in 1989 and prior to that, taught in the Mathematics Department at Fordham University and worked in the Business Research Group at JC Penney Corporate Headquarters. Tom earned a PhD (1989) in Operations Research from Columbia University, and a BS in Mathematics from SUNY Stony Brook. His email address is <ervolina@us.ibm.com>.

MARKUS ETTL is a Research Staff Member at IBM's T.J. Watson Research Center. Markus joined IBM Research in 1995 after receiving his doctoral degree in Computer Science in 1995 from Friedrich-Alexander University in Erlangen, Germany. Since joining IBM, he focused on advanced research in supply chain management. His research interests include operations research, simulation, decision support for manufacturing logistics, and sense- and-respond business management for adaptive organizations. His email address is <msettl@us.ibm.com>.

YOUNG M. LEE works in the Mathematical Sciences department of IBM's T.J. Watson Research Center, U.S.A., in the areas of supply chain simulation and optimization. Prior to joining IBM, he had worked for BASF, where he had founded and managed the Mathematical Modeling Group, and led development of numerous optimization and simulation models for various logistics and manufacturing processes. Recently at IBM, he developed several complex simulation models that are instrumental in analyzing and improving business processes, supply chain and IT solutions. He has a B.S., a M.S., and a Ph.D. degree in Chemical Engineering from Columbia University in the City of New York. His research interests include simulation and optimization of supply chain, manufacturing and business processes. His email address is <ymlee@us. i.bm. com>.

DANIEL J. PETERS works in IBM's Supply Chain Business Transformation. Dan joined IBM upon his retirement from the US Marine Corps seven years ago. Dan is a retired Marine Lieutenant Colonel with an extensive infantry, special operations, supply and logistics background. Dan has a B.S. in Mathematics from the University of Saskatchewan, MBA from Boston University, MA in National Security and Strategic Studies from the Naval War College, and an Advanced Certificate in Public Policy Analysis from Old Dominion University. His research interests include demand and supply conditioning. His email address is <petersdj@us.ibm.com>. 